\title{
Construction of a new questionnaire for assessing physical therapy student attitudes towards their education and profession and testing its validity and reliability
}

\author{
Jaya Shanker Tedla \\ Department of Medical Rehabilitation Sciences, College of Applied Medical Sciences, King Khalid University, Abha, Saudi Arabia
}

Objective: During the physical therapy education, if we can understand the student's attitude then we can make valuable suggestions with respect to the teaching in the universities and professional employment in the country. The aim of the current study is to develop a questionnaire to test the physical therapy students' attitudes towards their education and profession and to test its test-retest reliability and content validity.

Design: Cross-sectional study.

Methods: A total of 47 physical therapy students who were in their final year were randomly selected to participate in the study. After the making of the questionnaire, it was given to 6 professional experts teaching in the field of physical therapy to obtain their responses for each question with a 5-point Likert scale grading. Their answers were used in making the content validity of the questionnaire. Afterwards, the physical therapy students were asked to fill the questionnaire. Instrument reliability and test-retest reliability were also assessed by having the students complete the questionnaire after one month of taking the questionnaire.

Results: The content validity index was 0.71 for the whole scale and values of individual subdivisions were ranging from 0.69 to 0.75 . Instrument reliability measured by Cronbach's alpha coefficient was 0.86 for the whole scale and subdivision values were ranging from 0.32 to 0.86 . Test-retest reliability was assessed by intraclass correlation coefficient, which was 0.71 for whole scales and subdivision values were ranging from 0.38 to 0.70 .

Conclusions: This questionnaire, which assesses the physical therapy student attitude towards their education and profession, has good content validity, instrument reliability, and test-retest reliability.

Key Words: Attitude, Education, Physical therapy, Students, Surveys and questionnaires

\section{Introduction}

Excellency has no limitations or boundaries, all the education courses are trying to achieve this excellency by constantly improving their way of education. physical therapy is one such profession where the Excellency is growing to the higher limits with each decade. "physical therapy provides services to individuals and populations to develop, maintain and restore maximum movement and functional ability throughout the lifespan. This includes providing services in circumstances where movement and function are threatened by aging, injury, pain, diseases, disorders, conditions or environmental factors" [1]. In countries like the Kingdom of Saudi Arabia and India, the physical therapy is a profession where after completion of the bachelor levels the students will become qualified physical therapist and is expected to deal with their clients independently and effectively.

Attitude means a settled way of thinking or feeling about something [2]. There are many studies which tried to assess student attitudes towards the persons with disability $[3,4]$, elderly [5,6], Evidence-based practice [7], inter professional education [8], personal health behaviors [9], academic dis-

Received: 2 February, 2017 Revised: 10 March, 2017 Accepted: 14 March, 2017

Corresponding author: Jaya Shanker Tedla

Department of Medical Rehabilitation Sciences, College of Applied Medical Sciences, King Khalid University, 3665, Abha, Saudi Arabia Tel: 966-538901083 E-mail: jtedla@kku.edu.sa

(c) This is an Open-Access article distributed under the terms of the Creative Commons Attribution Non-Commercial License (http://creativecommons.org/licens es/by-nc/4.0) which permits unrestricted non-commercial use, distribution, and reproduction in any medium, provided the original work is properly cited.

Copyright $\odot 2017$ Korean Academy of Physical Therapy Rehabilitation Science 
honesty [10] and physical therapy assisstants [11] etc. But the attitude of physical therapy students towards their education and profession was studied only in few studies [12-14]. physical therapy student attitude towards their education and profession is very important to understand following things like how is their learning, are they satisfied with what they are learning and are they satisfied with their choice of profession or any regrets. All these findings from students will provide a window of opportunity for the educationist to change the education as per the student needs and make them responsible for their professional development.

Gotlib et al. $[13,14]$ studied the attitudes of physical therapy students towards their profession in Europe and provided the valuable suggestions regarding the employment and Tedla et al. [12] assessed the physical therapy student attitude towards their profession and education in India and provided suggestions for modifications in the teaching aspects. physical therapy professional education is in the mature stage and at this particular time if we can find the attitude of students toward their education and profession it will be easy to make any changes for future generation physical therapy educational programs so that any country will be benefited with the effective professionals in the physical therapy profession. There should be some sort of student attitude questionnaire which assesses this purpose. As a physical therapy educationist, we have developed a questionnaire by consulting students, interns, practicing Physical Therapist and teachers of physical therapy. Before getting a large number of the student's responses we want to see the test-retest reliability and content validity of this questionnaire so that future application will have good meaning in terms of consistency and authority.

\section{Methods}

After taking the ethical committee (REC\#2017-01-12) approval, 5 students of physical therapy, 5 practicing Physical Therapists and 5 teachers of physical therapy were asked independently about the purpose of this article to develop a questionnaire to assess the student attitude towards their education and profession. The students who consulted were studying final year in physical therapy. The practicing Physical Therapist who was consulted was having at least 5 years of clinical experience, after their master of physical therapy. The teachers of physical therapy who was consulted was having at least 5 years of teaching experience after their master of physical therapy.
By the discussions we were able to determine 4 subdivisions of the questionnaire the first one is, are the students happy with the choice of their profession/course, second do the students anticipate a good future, third are the students have good patient exposure and fourth are the students satisfied with their learning. Under each sub division there are 5 to 7 questions pertaining to the topic and each question will be answered either absolutely agree, agree, don't know, disagree and absolutely disagree. In this questionnaire there are total 25 questions and we followed five-point Likert scale grading that is absolutely agree is five grade, agree is four grade, don't know is three grade, disagree is two grade and absolutely disagree is one grade except for question number 6,8 , and 19 where the grades are reversed to keep the attention of the reader (Appendix).

After completing the making of the questionnaire we have circulated it to the 6 professional experts in the physical therapy teaching field who have 5 to 10 years of teaching experience and we obtained their response for each question under the 5 headings like either absolutely agree, agree, don't know, disagree, and absolutely disagree. These answers were used in making the content validity of the questionnaire.

After this, we have chosen 50 ( 25 males and 25 females) physical therapy final year students randomly by using a random number table as per their university numbers. The students are explained about the purpose of this research and asked to fill the questionnaire. During the filling of the questionnaire, students were sitting apart from each other so that their own decisions will reflect on the answers and any help to understand the questions were provided as and when necessary. After filling the questionnaire the student was given the gap of one month and after that questionnaire was filled by the students again to obtain the test-retest reliability. Only 47 were taken into consideration because 3 male students filled the questionnaire incompletely.

IBM SPSS Statistics ver. 19.0 (IBM Co., Armonk, NY, USA) was used for statistical analysis. The instrument validation was calculated by content validity index. The instrument reliability was assessed by Cronbach's alpha coefficient. The test-retest reliability was assessed by the intraclass correlation coefficient [15]. 


\section{Results}

\section{Instrument validation}

Items of the questionnaire were validated by experts using a content validity index [16]. Using a two-stage validation methodology, the first phase is developmental as the domains are identified, questions are generated, and the instrument is formulated. This phase of the validation was performed by the researchers and reviewed by a panel of 5 experts. The second phase of Lynn's validation is the judgment-quantification stage. In this stage, there are two parts: the first is the assertion by a specific number of experts that the items used on a five-point scale have valid content and that the instrument is valid. Six experts participated in this validation. Table 1 shows the content validity index of each expert which was ranged from 0.69 to 0.75 . At least four of the six experts reported scores more than 3 for the items. In the second part, the experts also assessed the overall instrument as valid as they had no further recommendations for additional content.

\section{Instrument reliability}

Internal consistency was calculated for the total sample of 47 male and female students. Cronbach's alpha coefficient was 0.86 for the total questionnaire and for each domain ranged from 0.32 to 0.86 (Table 2 ).

\section{Test ${ }^{-}$retest reliability}

Test-retest reliability was demonstrated in a sample of 47

Table 1. Content validity index of each domain

\begin{tabular}{lc}
\hline Domain & Content validity index \\
\hline A & 0.71 \\
B & 0.69 \\
C & 0.71 \\
D & 0.75 \\
Overall & 0.71 \\
\hline
\end{tabular}

Table 2. Cronbach's alpha coefficient of each domain for all the students

\begin{tabular}{lc}
\hline Domain & Cronbach's alpha coefficient \\
\hline A & 0.64 \\
B & 0.32 \\
C & 0.86 \\
D & 0.53 \\
Overall & 0.86 \\
\hline
\end{tabular}

students who were reassessed 1 month after the initial administration of the questionnaire. The means for all the subscales and for the total score at the two assessment intervals are presented in Table 3. The test-retest correlation coefficient for the total score was 0.71 in 1 month. Test-retest correlation coefficients for domain scores at 1 month were ranging from 0.38 to 0.70 .

\section{Discussion}

The aim of the current study is to develop a questionnaire to test the physical therapy student attitude towards their education and profession and to test its reliability and validity. We were able to formulate the questionnaire and test the reliability and validity of the whole questionnaire and to the individual subdivisions of the questionnaire. Even though whole questionnaire scale level content validity index is 0.71. Polit and Beck [17] review on content validity index had indicated that 0.80 of the scale level content validity index was recommended. We got 0.71 which may not be excellent but it is a good start for a new questionnaire.

Tavakol and Dennick [18] had described acceptable values of Cronbach's alpha coefficient which was ranged between 0.70 to 0.95 by various authors. Cronbach's alpha is very vital while describing the internal consistency reliability of any Likert-type scale of questionnaire [19]. Overall Instrument reliability measured by Cronbach's alpha coefficient for our scale was 0.86 which is in the well-accepted range given by Cronbach and Shavelson [20].

A study done by Moely et al. [21] had described psychometric properties of Civic Attitudes and Skills Questionnaire. This scale measures attitude of students towards their service learning. They have used statistics like Cronbach's alpha for measuring internal consistency and Pearson $r$ for test-retest reliability. They reported similar values, their Cronbach's alpha values were ranging from 0.69 to 0.88 and

Table 3. Mean scores and SD for each occasion in test-retest analysis

\begin{tabular}{lccc}
\hline Domain & Time 1 & Time 2 & $\begin{array}{c}\text { Correlation } \\
\text { coefficient }\left(\mathrm{r}_{1}\right)\end{array}$ \\
\hline A & $21.59(2.41)$ & $22.19(3.11)$ & 0.38 \\
B & $17.78(3.21)$ & $17.56(2.83)$ & 0.70 \\
C & $25.22(5.51)$ & $26.11(5.47)$ & 0.51 \\
D & $25.04(3.04)$ & $24.11(3.60)$ & 0.52 \\
Overall & $89.63(9.20)$ & $89.96(12.3)$ & 0.71 \\
\hline
\end{tabular}

Values are presented as mean (SD). 
Pearson $\mathrm{r}$ values were ranging from 0.56 to 0.81 . In our study, Cronbach's alpha values were ranging from 0.32 to 0.86 and ICC values were ranging from 0.38 to 0.70 .

Some of the individual domains have poor reliability like 0.32 for domain $B$ which is, are the students anticipate good future. This may be due to student's difficulty in anticipating the future and it entirely depends on an individual's mood and experiences which happened to them previously. Domain A and D reliability were 0.64 and 0.53 respectively, the reasons for the lack of consistency may be due to the gap between the two measurements. We have given 1-month gap to test the instrument reliability and in this one month, many factors can influence the student's opinion which might have altered the scoring.

The overall test-retest reliability of the questionnaire was 0.71 which was good. Weir [22] described interpretation guidelines for using intraclass correlation coefficient for assessing test-retest reliability. As per their guidelines any value near to one is excellent and values more than 0.60 are acceptable. Individual subdivisions had scored as low as 0.38 for domain A which is are the students happy with the choice of their profession/course. This may be due to their confusion in answering whether they had taken a right decision or not which varied with the one month time.

There are certain limitations like a number of students taken for the test-retest reliability are low, testing of reliability is done only for one college students. These can be overcome by planning a multi centric trial on a larger population to provide more accuracy in the psychometric properties.

The lack of reliability in subdivisions of A and B can be further studied with some modifications in the questionnaire, otherwise, the test-retest reliability and content validity of the whole questionnaire is sufficient enough to use it during the day to day practice.

We conclude that the questionnaire which assesses the physical therapy student attitude towards their education and profession has good content validity by having content validity index 0.71 and good instrument reliability with Cronbach's alpha coefficient 0.86 and test-retest reliability measured by test-retest correlation coefficient was 0.71 .

\section{Acknowledgements}

I thank Dr. Pranay Jindal, Dr. Sharada Nayak and my fellow, Physical Therapists who helped me in formulating this Questionnaire. I sincerely express my gratitude to Dr. Nabil
Girgis and Dr. Ismaeel Bin Jaliah, Associate Professors, College of Medicine, King Khalid University, Abha for helping me in this study.

\section{Conflict of Interest}

The authors declared no potential conflicts of interest with respect to the authorship and/or publication of this article.

\section{References}

1. World Confederation for Physical Therapy. Policy statement: standards of physical therapist practice. London: WCPT; 2011.

2. Oxford Living Dictionaries [Internet]. New York: Oxford University Press, 2017 [cited 2017 Jan 12]. Available from: http://www.oxforddictionaries.com/definition/english/attitude/.

3. Perry T, Conner A, Shelar D. Recreation student attitudes towards persons with disabilities: considerations for future service delivery. J Hosp Leis Sport Tour Educ 2008;7:4-14.

4. Uysal A, Albayrak B, Koçulu B, Kan F, Aydın T. Attitudes of nursing students toward people with disabilities. Nurse Educ Today 2014;34:878-84.

5. Bensadon BA, Teasdale TA, Odenheimer GL. Attitude adjustment: shaping medical students' perceptions of older patients with a geriatrics curriculum. Acad Med 2013;88:1630-4.

6. Samra R, Griffiths A, Cox T, Conroy S, Knight A. Changes in medical student and doctor attitudes toward older adults after an intervention: a systematic review. J Am Geriatr Soc 2013;61: 1188-96.

7. Stronge M, Cahill M. Self-reported knowledge, attitudes and behaviour towards evidence-based practice of occupational therapy students in Ireland. Occup Ther Int 2012;19:7-16.

8. Rose MA, Smith K, Veloski JJ, Lyons KJ, Umland E, Arenson CA. Attitudes of students in medicine, nursing, occupational therapy, and physical therapy toward interprofessional education. J Allied Health 2009;38:196-200.

9. Black B, Marcoux BC, Stiller C, Qu X, Gellish R. Personal health behaviors and role-modeling attitudes of physical therapists and physical therapist students: a cross-sectional study. Phys Ther 2012;92:1419-36.

10. Montuno E, Davidson A, Iwasaki K, Jones S, Martin J, Brooks $\mathrm{D}$, et al. Academic dishonesty among physical therapy students: a descriptive study. Physiother Can 2012;64:245-54.

11. Cavallo CL, Richter RR. Attitudes of physical therapist students toward physical therapist assistants before and after full-time clinical internships. J Allied Health 2004;33:10-6.

12. Tedla JS, Nayak S, Jindal P, Bipin P. Physiotherapy students attitude towards their education and profession. Physiother Occup Ther J 2009;2:127-8.

13. Gotlib J, Białoszewski D, Opavsky J, Garrod R, Fuertes NE, Gallardo LP, et al. Attitudes of European physiotherapy students towards their chosen career in the context of different educational systems and legal regulations pertaining to the practice of physiotherapy: implications for university curricula. Physiotherapy 
2012;98:76-85.

14. Gotlib J, Białoszewski D, Sierdziński J, Jarosz MJ, Majcher P, Barczyk K, et al. A comparison of the perceptions and aspirations of third-year physiotherapy students trained in three educational settings in Poland. Physiotherapy 2010;96:30-7.

15. Yen M, Lo LH. Examining test-retest reliability: an intra-class correlation approach. Nurs Res 2002;51:59-62.

16. Lynn MR. Determination and quantification of content validity. Nurs Res 1986;35:382-5.

17. Polit DF, Beck CT. The content validity index: are you sure you know what's being reported? Critique and recommendations. Res Nurs Health 2006;29:489-97.

18. Tavakol M, Dennick R. Making sense of Cronbach's alpha. Int J Med Educ 2011;2:53-5.

19. Gliem JA, Gliem RR. Calculating, interpreting, and reporting
Cronbach's alpha reliability coefficient for likert-type scales. Paper presented at: 2003 Midwest Research to Practice Conference in Adult, Continuing, and Community Education; 2003 Oct 8-10; Columbus, OH, USA. p. 82-8.

20. Cronbach LJ, Shavelson RJ. My current thoughts on coefficient alpha and successor procedures. Educ Psychol Meas 2004;64: 391-418.

21. Moely BE, Mercer SH, Ilustre V, Miron D, McFarland M. Psychometric properties and correlates of the Civic Attitudes and Skills Questionnaire (CASQ): a measure of students' attitudes related to service-learning. Mich J Community Serv Learn 2002;8:15-26.

22. Weir JP. Quantifying test-retest reliability using the intraclass correlation coefficient and the SEM. J Strength Cond Res 2005; 19:231-40. 
Appendix. Questionnaire for physical therapy student's attitude towards their profession and education We are trying to answer following questions through this questionnaire
A) Are the students happy with the choice of their profession/course
B) Do the students anticipate a good future
C) Are the students have good patient exposure
D) Are the students satisfied with their learning

\begin{tabular}{|c|c|c|c|c|c|c|c|}
\hline No. & SD & Questions & AA & A & DK & $\mathrm{D}$ & $\mathrm{AD}$ \\
\hline 1. & A & Physical Therapy is my choice of profession? & 5 & 4 & 3 & 2 & 1 \\
\hline 2. & & I was aware of the course before joining? & 5 & 4 & 3 & 2 & 1 \\
\hline 3. & & I joined Physical Therapy because I wanted to be a Physical Therapist. & 5 & 4 & 3 & 2 & 1 \\
\hline 4. & & I feel that my potentials have been rightly utilized in this course. & 5 & 4 & 3 & 2 & 1 \\
\hline 5. & & $\begin{array}{l}\text { I receive good respect and regards from people who know that I have chosen } \\
\text { this field. }\end{array}$ & 5 & 4 & 3 & 2 & 1 \\
\hline 6. & & $\begin{array}{l}\text { My extracurricular activities and hobbies have reduced after joining this } \\
\text { course. }\end{array}$ & 1 & 2 & 3 & 4 & 5 \\
\hline 7. & $\mathrm{~B}$ & I was aware of the job prospects before joining the course? & 5 & 4 & 3 & 2 & 1 \\
\hline 8. & & Sometimes I feel like changing my profession. & 1 & 2 & 3 & 4 & 5 \\
\hline 9. & & $\begin{array}{l}\text { I feel that other professionals are well aware of the scope and work nature of } \\
\text { the Physical Therapist. }\end{array}$ & 5 & 4 & 3 & 2 & 1 \\
\hline 10. & & $\begin{array}{l}\text { I am satisfied with the education and I am ready to work as a Physical } \\
\text { Therapist in the future. }\end{array}$ & 5 & 4 & 3 & 2 & 1 \\
\hline 11. & & I would recommend many others to join this course. & 5 & 4 & 3 & 2 & 1 \\
\hline 12. & $\mathrm{C}$ & Clinical postings are available for me in the hospitals. & 5 & 4 & 3 & 2 & 1 \\
\hline 13. & & $\begin{array}{l}\text { I have a good theoretical background regarding the patient assessment and } \\
\text { treatment. }\end{array}$ & 5 & 4 & 3 & 2 & 1 \\
\hline 14. & & $\begin{array}{l}\text { I have sufficient opportunity to observe patient assessment and treatment by } \\
\text { my teachers/experts. }\end{array}$ & 5 & 4 & 3 & 2 & 1 \\
\hline 15. & & $\begin{array}{l}\text { The theoretical teaching is mostly associated with patient assessment and } \\
\text { treatment. }\end{array}$ & 5 & 4 & 3 & 2 & 1 \\
\hline 16. & & $\begin{array}{l}\text { I have an excellent opportunity to assess a case and discuss it with my } \\
\text { teachers. }\end{array}$ & 5 & 4 & 3 & 2 & 1 \\
\hline 17. & & $\begin{array}{l}\text { Wide ranges and variety of cases are seen by me in my clinical postings at the } \\
\text { hospital. }\end{array}$ & 5 & 4 & 3 & 2 & 1 \\
\hline 18. & & I am satisfied with the patient exposure in my level. & 5 & 4 & 3 & 2 & 1 \\
\hline 19. & $\mathrm{D}$ & $\begin{array}{l}\text { I feel the profession is developing fast. And whatever we are learning are } \\
\text { very old concepts. }\end{array}$ & 1 & 2 & 3 & 4 & 5 \\
\hline 20. & & Continued medical education and workshops helps in learning. & 5 & 4 & 3 & 2 & 1 \\
\hline 21. & & I feel more of classroom teaching helps to gain knowledge. & 5 & 4 & 3 & 2 & 1 \\
\hline 22. & & $\begin{array}{l}\text { Self-learning enhances my learning and I have opportunities of self-learning } \\
\text { in my courses. }\end{array}$ & 5 & 4 & 3 & 2 & 1 \\
\hline 23. & & $\begin{array}{l}\text { I think this entry level bachelor course is apt for me to apply whatever I have } \\
\text { learnt. }\end{array}$ & 5 & 4 & 3 & 2 & 1 \\
\hline 24. & & I feel clinical teaching available to the students is appropriate. & 5 & 4 & 3 & 2 & 1 \\
\hline 25 & & $\begin{array}{l}\text { I feel I am learning more and more about Physical Therapy as my courses are } \\
\text { progressing. }\end{array}$ & 5 & 4 & 3 & 2 & 1 \\
\hline
\end{tabular}

No.: number of the question, SD: sub division of the questionnaire, AA: absolutely agree, A: agree, DK: don't know, D: disagree, AD: absolutely disagree. 